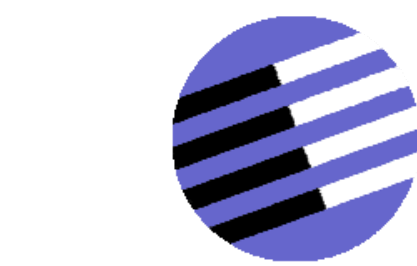

GOVERNANCE AND THE EFFICIENCY

OF ECONOMIC SYSTEMS

GESY

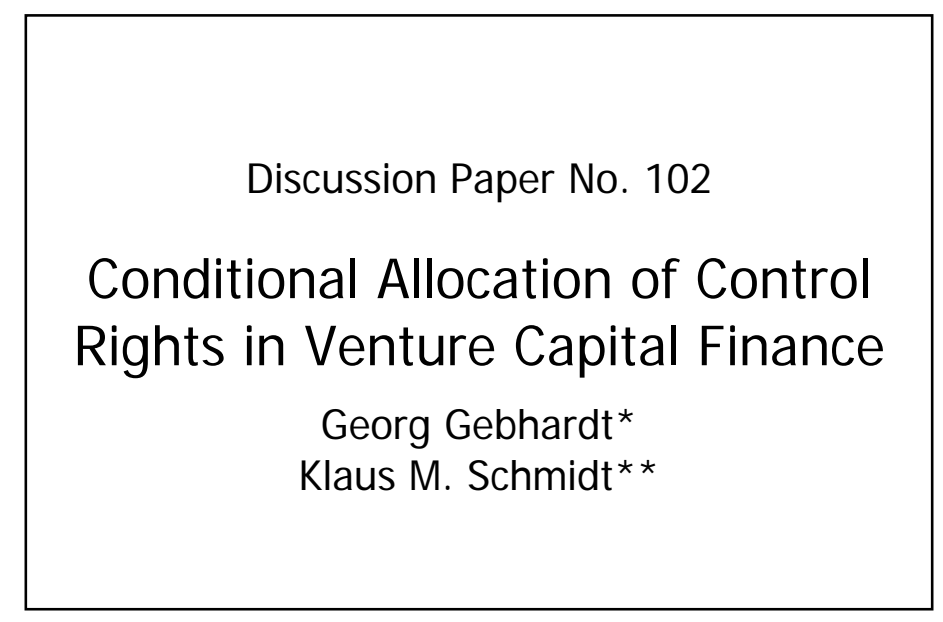

February 2006

*Georg Gebhardt, Department of Economics, University of Munich, Ludwigstr. 28 (Rgb.), D-80539 München, Germany. georg.gebhardt@Irz.uni-muenchen.de

**Klaus M. Schmidt, Department of Economics, University of Munich, Ludwigstr. 28 (Rgb.), D-80539 München, Germany. klaus.schmidt@Irz.uni-muenchen.de

Financial support from the Deutsche Forschungsgemeinschaft through SFB/TR 15 is gratefully acknowledged. 


\title{
Conditional Allocation of Control Rights in Venture Capital Finance ${ }^{\S}$
}

\author{
Georg Gebhardt* \\ University of Munich \\ Klaus M. Schmidt** \\ University of Munich, CEPR and CESifo
}

February 2006

\begin{abstract}
When a young entrepreneurial firm matures, it is often necessary to replace the founding entrepreneur by a professional manager. This replacement decision can be affected by the private benefits of control enjoyed by the entrepreneur which gives rise to a conflict of interest between the entrepreneur and the venture capitalist. We show that a combination of convertible securities and contingent control rights can be used to resolve this conflict efficiently. This contractual arrangement is frequently observed in venture capital finance.
\end{abstract}

JEL ClASSIFICATION NUMBERS: D23, G24, G32

Keywords: Corporate Finance, Venture Capital, Control Rights, Convertible Securities.

\footnotetext{
§Financial support by Deutsche Forschungsgemeinschaft through SFB-TR 15 is gratefully acknowledged.

*Department of Economics, University of Munich, Ludwigstr. 28 (Rgb.), D-80539 München, Germany, email: georg.gebhardt@lrz.uni-muenchen.de.

** Department of Economics, University of Munich, Ludwigstr. 28 (Rgb.), D-80539 München, Germany, email: klaus.schmidt@lrz.uni-muenchen.de.
} 


\section{Introduction}

The financing of young and highly risky companies is plagued by serious problems of asymmetric information and incentives that make it difficult for these firms to obtain bank loans or outside equity. In recent years venture capital firms have developed a sophisticated set of innovative financing instruments that can be used to mitigate these problems. In a detailed empirical study on venture capital finance in the US Kaplan and Strömberg (2003) find that the two most common and most important instruments are the predominant use of convertible securities and the contingent allocation of control rights that are often separated from cash flow rights.

A convertible security gives the VC firm the right to convert debt (or preferred stock) into equity if the portfolio company turns out to be very successful. This gives rise to a state contingent allocation of cash flow rights. Furthermore, venture capital contracts contain detailed provisions on the allocation of control rights. For example, even if the VC firm holds only a small fraction of the common stock of the firm, it may still have effective control over the board, sometimes directly through reserved seats, sometimes through a disproportionate share of votes. ${ }^{1}$ Other examples include clauses that require the approval of venture investors for asset sales or large expenditures. ${ }^{2}$ These additional rights are typically lost upon conversion. Thus, even though the cash flow rights of the VC firm increase with conversion, the venture capitalist may be left with less control rights.

In this paper we want to better understand the implications of a state contingent allocation of control rights. In particular, we offer an explanation for the stylized fact that the entrepreneur/founder of the company gets the control rights if the company is a high flyer and succeeds with an IPO, while the VC is in control if the company is less successful and has to be either liquidated or sold

\footnotetext{
${ }^{1}$ See Kaplan and Strömberg (2003) p. 287-290. Other examples include clauses that require the approval of venture investors for asset sales or large divestures.

${ }^{2}$ See Gompers (1999), Table 5.
} 
to another company. Furthermore, we show that it may be necessary to separate cash flow and control rights.

Our model is based on two observations: First, many entrepreneurs are not only motivated by the monetary returns of their efforts but also by private benefits that may accrue to them. For example, some entrepreneurs have a strong academic background and are interested in the scientific merits of their project even if these are of little commercial value. Some entrepreneurs feel a strong responsibility for the environment or their home region and may be willing to take decisions that are not optimal from a pure profit maximizing point of view. Empirical research suggests that these benefits are large compared even with the monetary rewards of entrepreneurship.

Second, the talents needed to invent a new business model and build a company from scratch are very different from those needed to run an established business. In the long run it can be beneficial from a profit maximizing point of view to replace the founder of a company by an outside manager. It is frequently observed that entrepreneurs leave their companies after the company matured, in particular when the company has been only moderately successful or if it has been sold through a trade sale to another company.

Taken together these two stylized facts create a trade off as to who should take the decision whether to replace the entrepreneur. The entrepreneur will never own all the cash flow rights, while she enjoys all the private benefits. Hence, she is unlikely to remove herself, even if it was efficient to do so. The venture capitalist, on the other hand, ignores the private benefits and focuses exclusively on the monetary payoff, when taking the replacement decision. Therefore, he may replace the entrepreneur, even if it was efficient to let her run the company.

If the firm is unsuccessful and the entrepreneur turns out to be unsuited to run the company, control should lie with the venture capitalist to ensure that an outside manager is hired. If the company is doing well and the entrepreneur turns out to be a sufficiently capable manager, the venture capitalist should relinquish 
control to prevent him from expropriating the entrepreneur's private benefits.

Often it is impossible to directly condition the control right on the state of the world. In these cases we show that the state of the world can implicitly be made contractible by linking control rights and cash flow rights. If properly constructed, the equity portion of a convertible security will be worth more than the debt part in the good state of the world, while it will be worth less in the bad state. Even if the conversion into equity forces the venture capitalist to give up his control rights, he may be convinced to do so by the higher value of the equity claim in the good state. In the bad state he will prefer a fixed claim to cash flows and thereby he keeps control. Hence, it is efficient to link cash flow and control rights such that conversion leads simultaneously to an increase in cash flow rights but to a decrease in control rights for the venture capitalist.

There are several other papers that deal with the use of convertible securities in venture capital financing. Cornelli and Yosha (2003) and Repullo and Suarez (2004) focus exclusively on the incentive properties of the conditional allocation of cash flow rights. Berglöf (1994) considers state contingent allocation of control rights through convertible securities and argues that they allocate control to the party that has the highest outside option, when negotiating with a potential buyer. Bascha and Walz (2001) argue that state contingent control rights are a way to implement the first best decision regarding IPO's.

Focusing on cash flow rights only, Schmidt (2003) shows with a related argument that convertible debt can implement efficient effort investment, if both the entrepreneur and the venture capitalist are important for the success of the project. Hellmann (1998) argues that it may be optimal for the entrepreneur to relinquish control to the venture capitalist to raise the funds necessary to start the venture. No argument is advanced, however, why this control right is tied to cash flow rights in the form of a convertible security.

The rest of the paper is organized as follows: In Section 2 we present the basic model. Section 3 shows that simple debt or equity contracts will in general 
not implement the first best, while we demonstrate in section 4 that a contingent control structure does. Section 5 the possibility of renegotiation. Section 6 concludes and shows that our conditional control structures can be interpreted as a convertible security combined with a control structure that is contingent on whether the venture capitalist exercises his conversion option.

\section{The Model}

Consider an entrepreneur (E) with an idea for a profitable project but no means to finance it. The project requires an initial investment $I$ that can be provided by a venture capitalist (V). Both parties are risk neutral. At date 0, E proposes a contract to $\mathrm{V}$ that governs their relationship. If $\mathrm{V}$ accepts the contract, they invest $I$. If $V$ rejects the contract, he gets a utility that is normalized to zero.

At date 1 , a state of the world denoted by $\theta \in\left\{\theta^{l}, \theta^{h}\right\}$ is realized. With probability $q$ the state is $\theta^{h}$. Then, at date $2, \mathrm{E}$ chooses the size of a private benefit $b \in[0, \bar{b}]$ that accrues to her and is non transferable. A higher private benefit $b$ reduces the expected monetary payoff of the project. At date 3 , the party in control of the project decides whether to replace E by an outside manager. Let $r \in\{0,1\}$ be an indicator variable that takes the value $r=1$ if $\mathrm{E}$ is replaced. At date 4 the final uncertainty resolves and nature determines whether the project fails and returns are zero or whether it succeeds and returns are $m(b, \theta)>0$. The probability of success depends on whether the firm is run by the entrepreneur or by the outside manager and is denoted by $p^{E}$ and $p^{R}$, respectively.

The time structure of the model is summarized in Figure 1:

\begin{tabular}{|c|c|c|c|c|}
\hline 0 & 1 & 2 & 3 & 4 \\
\hline $\begin{array}{c}\text { Contract; } \\
\text { Investment } I\end{array}$ & $\begin{array}{c}\text { Nature } \\
\text { determines } \\
\theta\end{array}$ & $\begin{array}{c}\text { E chooses } \\
b\end{array}$ & $\begin{array}{c}\text { Party in } \\
\text { control chooses } \\
r \in\{0,1\}\end{array}$ & $\begin{array}{c}\text { Project } \\
\text { succeeds or fails; } \\
\text { Payoffs }\end{array}$ \\
\hline
\end{tabular}

FIGURE 1: Time structure of the model 
The model focusses on the choice of private benefits of control by the entrepreneur at date 2 and on the decision to replace her at date 3 . Private benefits of control can be substantial. In an empirical study Moscovitz and VissingJorgensen (2002) use aggregate entrepreneurial equity return data and show that the value of private benefits to the entrepreneur amounts to 143 percent of total annual income. Furthermore, the entrepreneur may be willing to sacrifice expected monetary returns of the firm in order to increase her private benefits, i.e. $\frac{\partial m(b, \theta)}{\partial b}<0$. For example, she may want to invest in research projects that have a negativ net present value but advance her status as a researcher, she may consume perquisites such as a personal driver or a corporate jet, or she may employ friends or family in the firm even though they are not best suited for the job. If the entrepreneur is full residual claimant on the firm's profits and if she remains in control of the firm $(r=0)$ she will choose $b$ efficiently in order to maximize $p^{E} \cdot m(b, \theta)+b$. However, if $\mathrm{E}$ is replaced at date 3, all the private benefits are lost. Therefore, if replacement is anticipated, $b=0$ is efficient.

At date 3 the entrepreneur can be replaced by an outside manager. We assume that the probability of success is always higher with an outside manager than with the entrepreneur, i.e. $p^{R}>p^{E}$. The reason is that the entrepreneur of a young start-up company is typically not a professional manager. She came up with the idea for the project and she built up the company but she need not be best suited for running the company when it matures. Thus, expected monetary returns are always higher if $r=1$. On the other hand, if the entrepreneur is replaced, she loses her private benefits of control. Hence, if private benefits are sufficiently large, it may be more efficient not to replace E even though this reduces the expected monetary returns of the project. We assume that in state $\theta^{h}$ it is efficient to keep E while in state $\theta^{l} \mathrm{E}$ should be replaced. This is summarized in the following assumption:

Assumption 1 Let $b^{*}(\theta)=\arg \max \left\{p^{E} \cdot m(b, \theta)+b\right\}$ denote the efficient private benefit of $E$ in state $\theta$ if $E$ stays with the firm, while $b^{r}=0$ is efficient if $E$ is replaced. We assume that $m(b, \theta)$ is decreas- 
ing and strictly concave in $b$ and that $b^{*}(\theta)$ is unique with $0<b^{*}(\theta)<$ $\bar{b} \forall \theta \in\left\{\theta^{l}, \theta^{h}\right\}$. Furthermore,

$$
p^{E} \cdot m\left(b^{*}\left(\theta^{h}\right), \theta^{h}\right)+b^{*}\left(\theta^{h}\right)>p^{R} \cdot m\left(0, \theta^{h}\right)
$$

and

$$
p^{R} \cdot m\left(0, \theta^{l}\right)>p^{E} \cdot m\left(b^{*}\left(\theta^{l}\right), \theta^{l}\right)+b^{*}\left(\theta^{l}\right),
$$

i.e., it is efficient to keep $E$ in state $\theta^{h}$ and to let her consume $b^{*}\left(\theta^{h}\right)$ while in state $\theta^{l}$ private benefits are too small as compared to the loss in expected monetary returns and it is efficient to replace her.

The next assumption guarantees that it is efficient to carry out the project. Furthermore, it requires that the expected monetary return in the high state $\theta^{h}$ with the efficient benefit $b^{*}\left(\theta^{h}\right)$ is strictly larger than the expected monetary benefit in the low state $\theta^{l}$ if $\mathrm{E}$ choses $b=0$.

Assumption 2 If both parties behave efficiently the expected monetary return of the project is sufficient to cover the investment cost, i.e.

$$
I<q \cdot p^{E} m\left(b^{*}\left(\theta^{h}\right), \theta^{h}\right)+(1-q) p^{R} m\left(0, \theta^{l}\right) .
$$

Furthermore

$$
p^{R} m\left(0, \theta^{l}\right) \leq p^{E} m\left(b^{*}\left(\theta^{h}\right), \theta^{h}\right) .
$$

We can now be more specific about the feasible contracts that can be used to govern the project. The state of the world $\theta$ and the private benefit $b$ are observable by both parties but not verifiable to the courts and cannot be contracted upon. However, the parties can allocate control and cash flow rights. Let $C \in\{E, V\}$ denote who can decide whether or not to replace $\mathrm{E}$ at date 3, and let $v(m)$ denote the amount of money $\mathrm{V}$ gets at date 4 as a function of the monetary return of the project. $\mathrm{V}$ is only interested in his monetary payoff, so his utility function is given by

$$
U^{V}(m)=v(m)
$$


E's monetary payoff is $e(m)=m-v(m)$. However, she also cares about her privat benefits, so her utility function is given by

$$
U^{E}(m, b)=m-v(m)+b .
$$

We will first look at unconditional control structures that fix $(C, v(m))$ at date 0 for the entire relationship. However, the parties may also agree on a conditional control structures such as an option contract. For example, V could be given the option to choose at some point in time between dates 2 and 3 between control structure $\left(C^{1}, v^{1}(m)\right)$ and control structure $\left(C^{2}, v^{2}(m)\right)$. We will show that such a conditional control structure can be used to implement the first best in our model. Therefore, we do not look at more complicated contracts. We will also show that the conditional control structures that we consider closely resemble a combination of a convertible security and an allocation of control rights that is contingent on whether the venture capitalist exercises his conversion rights.

\section{Debt and Equity}

Let us first consider some standard unconditional control structures in order to show that they cannot be used to implement the efficient allocation.

Suppose that the parties finance the project with equity, i.e. $v(m)=\alpha m$ and $e(m)=(1-\alpha) m$. Note that because of E's wealth constraint and because $\mathrm{V}$ has to break even we must have $0<\alpha \leq 1$. The following proposition shows that no matter whether $\mathrm{E}$ is in control $(C=E)$ or $\mathrm{V}$ is in control $(C=V)$, the outcome is always inefficient.

Proposition 1 Any unconditional equity contract with $v(m)=\alpha m$, $0<\alpha \leq 1$ yields an inefficient allocation:

- If the venture capitalist gets the control right $(C=V)$ he chooses to replace the entrepreneur $(r=1)$ not only in state $\theta^{l}$ but also 
in state $\theta^{h}$. Thus, $V$ replaces $E$ too often because he does not take into account E's private benefits of control.

- If the entrepreneur gets the control right $(C=E)$ she chooses $b>b^{*}\left(\theta^{h}\right)$ in state $\theta^{h}$. Furthermore, there exists an $\underline{\alpha}<1$ such that for all $\alpha>\underline{\alpha}$ she chooses $r=0$ and $b>b^{*}\left(\theta^{l}\right)$ in state $\theta^{l}$. Thus, E consumes to many private benefits if she is in control.

Proof: Suppose that $C=V$. Note that $p^{R}>p^{E}$ implies $p^{R} \alpha m(b, \theta)>p^{E} \alpha m(b, \theta)$. Thus, for all $\alpha>0$ and all states $\theta \in\left\{\theta^{h}, \theta^{l}\right\} \mathrm{V}$ will replace $\mathrm{E}$, which is inefficient in state $\theta^{h}$.

Suppose now that $C=E$ and consider state $\theta^{h}$. If $E$ wants to choose $r=0$ at date 3 she will choose $b(\alpha)=\arg \max \left\{p^{E}(1-\alpha) m\left(b, \theta^{h}\right)+b\right\}$. Concavity of $m\left(\cdot, \theta^{h}\right)$ and $\alpha>0$ imply that $b(\alpha)>b^{*}$ and $b^{\prime}(\alpha)>0$. Furthermore, because $b^{*}(\alpha)$ maximizes E's payoff, we must have

$$
\begin{aligned}
p^{E}(1-\alpha) m\left(b(\alpha), \theta^{h}\right)+b(\alpha) & >p^{E}(1-\alpha) m\left(b^{*}, \theta^{h}\right)+b^{*} \\
& >p^{R}(1-\alpha) m\left(0, \theta^{h}\right)
\end{aligned}
$$

The last inequality follows from Assumption 1. Thus, in state $\theta^{h} \mathrm{E}$ will not remove herself (which is efficient). However, she will consume too many private benefits.

Consider now state $\theta^{l}$. If $\mathrm{E}$ removes herself at date 3, she should choose $b=0$ which yields an expected payoff of $p^{R}(1-\alpha) m\left(0, \theta^{l}\right)$. Note that this payoff goes to 0 as $\alpha$ goes to 1 . If $\mathrm{E}$ is anticipates that she is not going to remove herself, she should choose $b(\alpha)=\arg \max \left\{p^{E}(1-\alpha) m\left(b, \theta^{l}\right)+b\right\}$. Note that $p^{E}(1-\alpha) m\left(b(\alpha), \theta^{l}\right)+b(\alpha)$ is decreasing in $\alpha$ but bounded below by $\bar{b}$ because E can always guarantee herself at least $\bar{b}$ by choosing $b=\bar{b}$. Thus, there exists an $\underline{\alpha}<1$ such that for all $\alpha>\underline{\alpha}$ it must be optimal for E to choose $r=0$ and $b(\alpha)>b^{*}\left(\theta^{l}\right)$, both of which is inefficient.

Q.E.D.

The problem of equity with $\mathrm{V}$ control is that $\mathrm{V}$ has an incentive to replace $\mathrm{E}$ in both states of the world, because he does not take into account E's private 
benefits. Equity with $\mathrm{E}$ control is also inefficient: In state $\theta^{h} \mathrm{E}$ will choose $b<b^{*}\left(\theta^{h}\right)$ because she enjoys the full private benefits but has to pay only fraction $(1-\alpha)$ of the cost. Furthermore, in state $\theta^{l}$, E may have an incentive to stay in the firm because of the private benefits she enjoys, even though it would be more efficient if she left.

Next we consider a debt contract. A debt contract requires $E$ to make a fixed payment $D$ to $\mathrm{V}$ at date 4 . Note that in our model a debt contract is an unconditional control structure. The debt payment is due at date 4 when the returns of the firm accrue. Thus, even if the firm goes bankrupt at date 4 , all decisions that our model focusses on have been taken already.

For simplicity we will restrict attention to the case where E can repay her debt if the firm was successful at date 4 . Clearly, if the debt cannot be repaid in case of success, it would be even more difficult to achieve an efficient allocation with a debt contract.

Proposition 2 Any unconditional debt contract with $v(m)=D$ and $e(m)=m-D$ yields an inefficient allocation, if $D$ is sufficiently large.

- If the venture capitalist gets the control right $(C=V)$ he chooses to replace the entrepreneur $(r=1)$ not only in state $\theta^{l}$ but also in state $\theta^{h}$ in order to maximize the probability that the debt is repaid. Thus, $V$ replaces $E$ too often.

- If the entrepreneur gets the control right $(C=E)$ she chooses $b=b^{*}\left(\theta^{h}\right)$ in state $\theta^{h}$ which is efficient. However, in state $\theta^{l}$ she will not choose to remove herself if

$$
D>\frac{p^{R} m\left(0, \theta^{l}\right)-p^{E} m\left(b^{*}\left(\theta^{l}\right), \theta^{l}\right)-b^{*}\left(\theta^{l}\right)}{p^{R}-p^{E}}
$$

[It remains to be shown that this is a relevant case]

Proof: Suppose $C=V$. V's expected payoff with a debt contract is $p^{E} D$ if $\mathrm{E}$ stays in the firm and $p^{R} D$ if $\mathrm{E}$ is replaced. Therefore, $\mathrm{V}$ always wants to replace $\mathrm{E}$, even in state $\theta^{h}$ which is inefficient. 
Suppose now that $C=E$. In state $\theta^{h} \mathrm{E}$ will stay in the firm and choose $b$ efficiently because she is full residual claimant on the margin. In state $\theta^{l}$, however, E may have an incentive to stay in the firm even if it is more efficient to leave. If she stays, her expected payoff is $U^{E}=p^{E}\left[m\left(b, \theta^{l}\right)-D\right]-b=p^{E} m\left(b, \theta^{l}\right)-b-p^{E} D$, so she should choose $b=b^{*}\left(\theta^{l}\right)$. If she is replaced by an outside manager her payoff is $U^{E}=p^{R}\left[m\left(b, \theta^{l}\right)-D\right]$, so she should choose $b=0$. She prefers the former strategy to the latter iff

$$
p^{E}\left[m\left(b^{*}\left(\theta^{l}\right), \theta^{l}\right)-D\right]+b^{*}\left(\theta^{l}\right)>p^{R}\left[m\left(0, \theta^{l}\right)-D\right]
$$

which is equivalent to

$$
D>\frac{p^{R} m\left(0, \theta^{l}\right)-p^{E} m\left(b^{*}\left(\theta^{l}\right), \theta^{l}\right)-b^{*}\left(\theta^{l}\right)}{p^{R}-p^{E}} .
$$

Q.E.D.

The problem with a debt contract that gives control to $\mathrm{V}$ is that $\mathrm{V}$ will always replace $\mathrm{E}$ in order to maximize the probability that the debt is repaid. If, on the other hand, control is given to E, then E may be unwilling to remove herself but rather stay in charge and consume her private benefits. Part of the cost from doing so is born by $\mathrm{V}$ who receives his debt payment with a smaller probability if E stays in the firm.

Corollary 1 The efficient allocation cannot be implemented by any combination of debt and equity.

Corollary 1 follows immediately from Proposition 1 . Since any $\alpha>0$ induces inefficient behavior in at least one state of the world, so does any combination of equity and debt.

\section{Contingent Control Structures}

In this section we will show that a conditional control structure can be used to implement the first best efficient allocation even if debt or equity cannot. 
Proposition 3 Consider a convertible security $\{(D, V),(\alpha, E)\}$ which gives $V$ the right to choose at date 2.5 between a debt claim $D$ with $V$ control and an equity claim $\alpha$ with $E$ control. If $D$ and $\alpha$ are chosen such that

$$
D=\frac{I}{p^{R}}
$$

and

$$
\alpha=\frac{p^{R}}{p^{E}} \frac{D}{m\left(b^{*}\left(\theta^{h}\right), \theta^{h}\right)}=\frac{I}{p^{E} m\left(b^{*}\left(\theta^{h}\right), \theta^{h}\right)}<1
$$

then the convertible security induces $E$ and $V$ to behave efficiently in both states of the world.

Proof: We first analyze the contractual choice of $\mathrm{V}$ at date 2.5 for any given $b$. Consider first state $\theta^{l}$. If $\mathrm{V}$ chooses debt with $\mathrm{V}$ control, he will replace $\mathrm{E}$ at date 3 and his expected payoff is $U^{V}(D, V)=p^{R} \cdot D$. If he chooses equity and E control, then E will choose $r=1$ if and only if $p^{R}(1-\alpha) m\left(b, \theta^{l}\right)>p^{E}(1-\alpha) m\left(b, \theta^{l}\right)+b$ which is equivalent to

$$
\alpha<\frac{\left(p^{R}-p^{E}\right) m\left(b, \theta^{l}\right)-b}{\left(p^{R}-p^{E}\right) m\left(b, \theta^{l}\right)}<1
$$

If $\alpha$ is below this threshold, her profit share is sufficiently high that she will voluntary remove herself. In this case, V's expected payoff is $p^{R} \alpha m\left(b, \theta^{l}\right)$. If however, $\alpha$ is above the threshold, E's profit share is so small that she would rather not replace herself but consume $b$. In this case, V's expected payoff is $U^{V}(\alpha, E)=p^{E} \alpha m\left(b, \theta^{l}\right)<p^{R} \alpha m\left(b, \theta^{l}\right)$. Thus, $\mathrm{V}$ will always choose debt with $\mathrm{V}$ control if

$$
p^{R} \alpha m\left(b, \theta^{l}\right) \leq p^{R} D=p^{R} \frac{p^{E}}{p^{R}} \alpha m\left(b^{*}\left(\theta^{h}\right), \theta^{h}\right)
$$

which is equivalent to

$$
p^{R} m\left(b, \theta^{l}\right) \leq p^{E} m\left(b^{*}\left(\theta^{h}\right), \theta^{h}\right)
$$

which holds by Assumption 2.

Consider now state $\theta^{h}$. We first show that in equilibrium $\mathrm{V}$ will choose $(\alpha, E)$ if and only if $b \leq b^{*}$. Note first that if $\mathrm{V}$ chooses $(D, V)$, he will always replace $\mathrm{E}$ 
at date 3 in order to increase the probability that the debt is repaid. Thus, his expected payoff is $p^{R} D$. Second, if $\mathrm{V}$ chooses equity and $\mathrm{E}$ control, E will choose $r=0$ which is efficient. Furthermore, V's expected payoff $p^{E} \alpha m\left(b, \theta^{h}\right)$ is strictly increasing in $b$. Thus, by the construction of $\alpha$ we get that $p^{R} D \leq p^{E} \alpha m\left(b, \theta^{h}\right)$ if and only if $b \leq b^{*}\left(\theta^{h}\right)$. Thus, $\mathrm{V}$ will choose equity with $\mathrm{E}$ control if and only if $\mathrm{E}$ does not consume more than the efficient private benefits.

Now we analyze the optimal choice of $b$ by E. Consider state $\theta^{l}$ first. E anticipates that $\mathrm{V}$ will always go for debt with $\mathrm{V}$ control and that he will replace her at date 3 . Therefore, it is optimal for her to choose $b=0$.

Consider now state $\theta^{h}$. E anticipates that $\mathrm{V}$ will choose equity and E control if and only if $b \leq b^{*}\left(\theta^{h}\right)$ in which case she will stay on in the company and can consume her private benefits.

If she chooses $b>b^{*}\left(\theta^{h}\right), \mathrm{V}$ will choose $(D, V)$ and replace her at date 3 . Thus her expected payoff in this case is

$$
U^{E}\left(b>b^{*}\left(\theta^{h}\right)\right)=p^{R} \cdot\left[m\left(b, \theta^{h}\right)-D\right]
$$

which is strictly decreasing in $b$. Because of the constraint $b>b^{*}\left(\theta^{h}\right)$ E maximizes over an open set and there is no optimal value for $b$. However, the payoff that can be obtained with $b>b^{*}\left(\theta^{h}\right)$ is bounded above by

$$
\sup U^{E}\left(b>b^{*}\left(\theta^{h}\right)\right)=\lim _{b \rightarrow b^{*}} p^{R} \cdot\left[m\left(b, \theta^{h}\right)-D\right]=p^{R} \cdot\left[m\left(b^{*}\left(\theta^{h}\right), \theta^{h}\right)-D\right] .
$$

On the other hand, if she chooses $b \leq b^{*}\left(\theta^{h}\right) \mathrm{V}$ will opt for $(\alpha, E)$ and $\mathrm{E}$ will not be replaced. In this case her expected payoff is

$$
U^{E}(b)=p^{E}(1-\alpha) m\left(b, \theta^{h}\right)+b .
$$

In this case she would like to choose $b^{*}(\alpha)>b^{*}\left(\theta^{h}\right)$ but she is constrained by $b \leq b^{*}(\theta)$.

Thus, E will choose $b=b^{*}\left(\theta^{h}\right)$ if and only if

$$
\begin{aligned}
U^{E}\left(b^{*}\left(\theta^{h}\right)\right) & =p^{E}(1-\alpha) m\left(b^{*}\left(\theta^{h}\right), \theta^{h}\right)+b^{*}\left(\theta^{h}\right) \\
& \geq p^{R} \cdot\left[m\left(b^{*}\left(\theta^{h}\right), \theta^{h}\right)-D\right]=\sup U^{E}\left(b>b^{*}\left(\theta^{h}\right)\right) .
\end{aligned}
$$


Substituting $\alpha=\frac{p^{R}}{p^{E}} \frac{D}{m\left(b^{*}\left(\theta^{h}\right), \theta^{h}\right)}$ this is equivalent to

$$
p^{E}\left(1-\frac{p^{R}}{p^{E}} \frac{D}{m\left(b^{*}\left(\theta^{h}\right), \theta^{h}\right)}\right) m\left(b^{*}\left(\theta^{h}\right), \theta^{h}\right)+b^{*}\left(\theta^{h}\right) \geq p^{R} \cdot\left[m\left(b^{*}\left(\theta^{h}\right), \theta^{h}\right)-D\right]
$$

which is equivalent to

$$
p^{E} m\left(b^{*}\left(\theta^{h}\right), \theta^{h}\right)+b^{*}\left(\theta^{h}\right) \geq p^{R} m\left(b^{*}\left(\theta^{h}\right), \theta^{h}\right)
$$

which holds by Assumption 1.

Thus, we have shown that in the good state $\mathrm{V}$ will choose $(\alpha, E)$ if and only if $\mathrm{E}$ chooses $b \leq b^{*}\left(\theta^{h}\right)$ and that this induces $\mathrm{E}$ to choose $b=b^{*}\left(\theta^{h}\right)$, which is efficient.

It remains to be shown that $\alpha<1$. Note that Assumption 2 implies that $I<p^{E} m\left(b^{*}\left(\theta^{h}\right), \theta^{h}\right)$. Thus,

$$
\alpha<\frac{p^{E} m\left(b^{*}\left(\theta^{h}\right), \theta^{h}\right)}{p^{E} m\left(b^{*}\left(\theta^{h}\right), \theta^{h}\right)}=1 .
$$

Finally, we have to show that $\mathrm{V}$ recovers his investment cost I. In the bad state he gets $p^{R} D$. In the good state he gets $p^{E} \alpha m\left(b^{*}\left(\theta^{h}\right), \theta^{h}\right)=p^{R} D$. Thus, his expected payoff is

$$
q p^{r} D+(1-q) p^{r} D=p^{r} D=p^{R} \frac{I}{p^{r}}=I
$$

so he just breaks even.

The intuition for Proposition 3 is as follows. At date $2.5 \mathrm{~V}$ has to decide whether to take a debt claim and have control at date 3 or whether to have an equity claim and give control to E. In the bad state, the equity claim is worth little and V prefers to replace $\mathrm{E}$ in order to get the fixed payment $D$ with a higher probability. Consider now the good state. $D$ and $\alpha$ have been chosen such that $\mathrm{V}$ prefers equity over debt if and only if E chose $b \leq b^{*}\left(\theta^{h}\right)$. E anticipates that if she chooses $b>b^{*}\left(\theta^{h}\right), \mathrm{V}$ will take debt with $\mathrm{V}$ control and replace her at date 3. Therefore, she will resist the temptation to consume to many private benefits and chooses $b=b^{h}(\theta)$ which is efficient. 
Note that $D$ and $\alpha$ have been chosen such that $\mathrm{V}$ just breaks even. He prefers the debt claim in the bad state where he receives $p^{R} D$. He prefers the equity claim in the good state where his expected payoff is $p^{E} \alpha m\left(b *\left(\theta^{h}\right), \theta^{h}\right)=p^{R} D$. Thus, his overall expected payoff is given by

$$
U^{V}=q p^{R} D+(1-q) p^{R} D-I=p^{R} \frac{I}{p^{R}}-I=0 .
$$

Thus, any efficient project that satisfies Assumptions 1 and 2 can be financed by using a contingent control structure.

\section{Renegotiation}

In this section we consider the possibility that the parties renegotiate the initial contract during their relationship. Their is an incentive to renegotiate the original contract whenever there is scope for an efficiency improvement. If the contract of Proposition 3 is in place, this cannot happen on the equilibrium path, because the contract implements an efficient allocation in all states of the world. It may, however, occur off the equilibrium path state $\theta^{h}$. To see this suppose that $\mathrm{E}$ chooses $b>b^{*}$. In this case $\mathrm{V}$ is induced to choose $(D, V)$ and to replace $\mathrm{E}$ which would be inefficient. Therefore $\mathrm{E}$ may offer to increase $\alpha$ in order to induce $\mathrm{V}$ to choose $(\alpha, E)$ and not to replace her. The following proposition shows, however, that E can never gain from choosing $b>b^{*}$.

Proposition 4 The contract of Proposition 3 implements the first best, even if renegotiation is feasible at any point in time.

Proof: First, note that under convertible financing there is no scope for renegotiations on the equilibrium path, because the first-best is implemented. In the bad state there cannot be renegotiation off the equilibrium path either. Suppose E chooses $b>0$, then $\mathrm{V}$ would still choose $(D, V)$, which is efficient. Thus, $\mathrm{E}$ has no incentive to deviate. 
If $\mathrm{E}$ chooses $b>b^{*}$ in the good state, $\mathrm{V}$ prefers $(D, V)$ over $(\alpha, E)$. But if he would choose $(D, V)$ he would not replace $\mathrm{E}$, which would be inefficient. Therefore, E could to increase $\alpha$ in order to induce $\mathrm{V}$ to behave efficiently. We have to distinguish two cases.

- $D \leq m\left(\hat{b}, \theta^{h}\right)$ : In this case $\mathrm{V}$ can secure himself $p^{R} D$, the same as on the equilibrium path, by sticking to $(D, V)$. Because the total surplus is reduced by deviating from $b^{*}$ that leaves less for $\mathrm{E}$ than on the equilibrium path. Therefore, it does not pay off for E do deviate.

- $D>m\left(\hat{b}, \theta^{h}\right)$ : In this case E the company would have to declare bankruptcy and the whole monetary payoff goes to $\mathrm{V}$. Therefore, even offering $\alpha=1$ will not induce $\mathrm{V}$ to relinquish control because he gets $m\left(\hat{b}, \theta^{h}\right)$ with the higher probability $p^{R}$ if he keeps his control right..

Q.E.D.

\section{Conclusion}

The contingent control structure that we used in Section 4 can be interpreted as a convertible security combined with a shift in control rights if the conversion option is exercised. For example, in the initial contract the venture capitalist could be given convertible debt or convertible preferred stock and in addition control rights over the company including the right to replace the entrepreneur. However, these control rights are lost if the venture capitalist chooses to convert his debt claim into equity. In this case, the entrepreneur receives full control. The venture capitalist will exercise his conversion option only if the firm is highly successful. Furthermore, the entrepreneur wants him to exercise his conversion option in order to receive the control over the company. Therefore, she is willing to consume not to many private benefits in order not to reduce the monetary value of the firm too much.

On the other hand, if the bad state of the world materializes, it it is not 
profitable for $\mathrm{V}$ to exercise his option. Therefore he will remain in control and replace E, which is efficient.

It interesting to note that cash flow rights and control rights move in opposite directions here. If $\mathrm{V}$ does not exercise his conversion option, he holds a debt claim, but he is assigned the control right to remove E. If $\mathrm{V}$ exercises his option, he holds equity. Nevertheless, the control rights are now passed to E. This is just the opposite of standard debt and equity. With standard debt, the debt holder has no control rights as long as the debtor is not in default, while the traditional equity holders have all the residual rights of control in a company.

Such a separation of cash flow rights and control rights is often observed in venture capital finance. 


\section{References}

Bascha, A., And U. Walz (2001): "Convertible Securities and Optimal Exit Decisions in Venture Capital Finance," Journal of Corporate Finance, 7, 285306.

BerglöF, E. (1994): “A Control Theory of Venture Capital Finance," Journal of Law, Economics and Organization, 10, 247-267.

Cornelli, F., And O. Yosha (2003): "Stage Financing and the Role of Convertible Securities," Review of Economic Studies, 70, 1-32.

Gompers, P. A. (1999): "Ownership and Control in Entrepreneurial Firms: An Examination of Convertible Securities in Venture Capital Investment.," Working Paper, Harvard Business School.

Hellmann, T. F. (1998): "The Allocation of Control Rights in Venture Capital Contracts," Rand Journal of Economics, 29, 57-76.

Kaplan, S. N., And P. Strömberg (2003): "Financial Contracting Theory Meets the Real World: An Empirical Analysis of Venture Capital Contracts," Review of Economic Studies, 70(2), 281-315.

Moscovitz, T., And A. Vissing-Jorgensen (2002): "The Returns to Entrepreneurial Investment: A Private Equity Premium Puzzle?," American Economic Review, 92(4), 745-778.

Repullo, R., and J. Suarez (2004): "Venture Capital Finance: A Security Design Approach," Review of Finance, 8(1), 75-108.

Schmidt, K. M. (2003): "Convertible Securities and Venture Capital Finance," Journal of Finance, 58(3), 1139-1166. 